\title{
EDITORIAL
}

\section{Editorial note: welcome to Volume 23 and the year 2020}

The Editorial Board of African Journal of Nephrology (AJN) and I wish all readers, contributors and reviewers a very happy and successful year 2020 .

The year 2019 was a very productive year for AJN and the African Association of Nephrology (AFRAN). The 2019 AFRAN congress, held from 25 to 29 September 2019 in Mombasa (Kenya), was a very successful one, with the participation of hundreds of delegates from all regions of Africa. The congress was held in partnership with the Kenya Renal Association and the African Paediatric Nephrology Association (AFPNA). The main congress was preceded by several successful courses. Prof Antony Were from Kenya was elected President of AFRAN. The next AFRAN congress will be held next year in Côte d'Ivoire.

In 2019, we published excellent reviews covering global disparities in kidney disease and its treatment as well as the use of data from renal registries in randomised controlled trials. We therefore encourage our readers to participate in the collection of data for registries as well as to make use of registry data for research. The AJN 2019 volume also published excellent original articles that showcased the strength of clinical nephrology research in various regions of Africa.

The year 2020 is expected to witness several national and regional nephrology meetings. I urge all convenors to use AJN to publicize their meetings, as well as publish their proceedings. The World Congress of Nephrology will take place in Abu Dhabi from 26 to 29 March 2020. This year, World Kidney Day is scheduled for Thursday, 12 March 2020.The theme is "Kidney Health for Everyone Everywhere - from Prevention to Detection and Equitable Access to Care".

I am confident that, in 2020, AJN will continue the trends set in the previous year, by publishing outstanding in-depth review articles as well as interesting original research articles.

Finally, I am pleased to announce that this year, the South African Renal Society Congress will take place in Durban at the International Convention Centre, from 25-29 November 2020. The theme of the congress is "Big Data and Access to Quality Renal Care". As President of the Local Organising Committee, I invite everyone to SARS Congress 2020.

WOZA - DURBAN!

\section{Alain G Assounga}

Editor-in-Chief 